UDC $1: 130.2$

LBC 87.53

\title{
TRANSFORMATION OF VALUE POSITIONS IN THE YOUTH ATTITUDE OF TO WORK: A PHILOSOPHICAL ANALYSIS
}

\author{
Roman A. Kobylkin \\ Volgograd Academy of the Ministry of Internal Affairs of Russia, Volgograd, Russian Federation
}

\begin{abstract}
Most representatives of the modern youth demonstrate formed clip thinking characterized by a loss of skills to analyze, discourse, set logical connections. This not only affects the process of learning and obtaining professional knowledge, but also expresses a change in the attitude to work as one of the most important values against the background of a significant increase in the value of leisure. The transformation of values due to the influence of external factors such as television, Internet, radio, media on consciousness is obvious. The bulk of the media clip thinking is the youth facing serious difficulties in introducing serious creative work and the creation of new values.

At present the structure and types of differences in employment are undergoing epoch-making changes. They are expressed in the mixture of traditional and modern trends, the emergence of new forms of work (freelance, downshifting, etc.), as well as in the formation of new trends in the attitude to work. New values such as "success", "pleasure", "power" are formed on the basis of cultural changes in the youth environment. The value paradigm formed in the youth environment under the influence of mass culture in the conditions of the information revolution has become an expression of new needs in the transformation of social reality. Under these conditions, the study of trends in the youth's value attitudes to work is of great theoretical and practical importance.

The theoretical basis of this article is grounded on the works of A. Mole, E. Toffler, D. bell, E. Fromm, G. Marcuse, G. McLuhan. Their research papers reflect the changes that began to occur in society in the second half of the XX century and had an impact on the change of value orientations of young people. In our country, these changes were manifested in the generation of the nineties and noughties, and the representatives of this generation are the carriers of new values associated with the consequences of the information revolution.
\end{abstract}

Key words: clip thinking, post-industrial society, labor, freelance, downshifting, intellectual labor, values.

УДК $1: 130.2$

ББК 87.53

\section{ТРАНСФОРМАЦИЯ ЦЕННОСТНЫХ УСТАНОВОК В ОТНОШЕНИИ МОЛОДЕЖИ К ТРУДУ: ФИЛОСОФСКИЙ АНАЛИЗ}

\author{
Роман Александрович Кобылкин \\ Волгоградская академия МВД России, г. Волгоград, Российская Федерация
}

\begin{abstract}
Аннотация. У большинства представителей современного молодого поколения формируется клиповое мышление, которое характеризуется утратой навыков анализировать, рассуждать, устанавливать логические связи. Это не только влияет на процесс обучения и получения профессиональных знаний, но и выражается в изменении отношения к труду как одной из важнейших ценностей на фоне существенного роста значения досуга. Очевидна трансформация ценностных установок в связи с влиянием на сознание внешних факторов, таких как телевидение, Интернет, радио, СМИ. Основная масса носителей клипового мышления это молодежь, которая сталкивается с серьезными трудностями приобщения к серьезному творческому труду и созданию новых ценностей.

В настоящее время структура и видовые различия трудовой деятельности переживают эпохальные изменения. Они выражаются в миксации традиционных и современных направлений, появлении новых форм труда (фриланс, дауншифтинг и др.), а также в формировании новых тенденций в отношении к труду.
\end{abstract}


На основе культурных изменений в молодежной среде формируются новые ценности, такие как «успех», «удовольствие», «могущество». Ценностная парадигма, сложившаяся в молодежной среде под воздействием массовой культуры в условиях информационной революции, стала выражением новых потребностей в условиях трансформации социальной реальности. В этих условиях исследование тенденций изменения ценностных установок в отношении молодежи к труду имеет большую теоретическую и практическую значимость.

Теоретической основой данной статьи явились работы А. Моля, Э. Тоффлера, Д. Белла, Э. Фромма, Г. Маркузе, Г. Маклюэна. Они отразили те изменения, которые начали происходить в обществе во второй половине ХХ века и оказали влияние на изменение ценностных ориентаций молодежи. В нашей стране эти изменения проявились в поколении девяностых и нулевых годов, представители которых являются носителями новых ценностей, связанных с последствиями информационной революции.

Ключевые слова: клиповое мышление, постиндустриальное общество, труд, фриланс, дауншифтинг, интеллектуальный труд, ценности.

Информационная революция, которая началась во второй половине XX века, произвела на свет совершенно новый тип человека. Если до этого периода формирование личности происходило под воздействием книжной культуры, в современном обществе под воздействием новых носителей информации телевидения, радио, Интернета - появляется «человек-экран». О таком человеке впервые написал французский социолог А. Моль в книге «Социодинамика культуры» (1967) [Моль 2008], выделив в качестве его особенности неспособность к системному мышлению, фрагментарность. О клиповом характере мышления человека в информационном обществе писал Э. Тоффлер в своем труде «Третья волна» (1980) [Тоффлер 2004]. Описывая в качестве продукта информационного общества «человека-экран», он отмечает в качестве сущностной характеристики его мышления умение обрабатывать одновременно звуковые и зрительные образы, что постепенно приводит к уменьшению рефлексивного восприятия, характерного для книжной культуры. Это оказывает влияние на обучение и трудовую деятельность «нового» человека, поскольку под воздействием электронных средств коммуникации изменяется его восприятие и когнитивные возможности.

С одной стороны, наиболее ценным ресурсом в обществе становятся высокий уровень образования, профессионализм и креативность, с другой - снижаются навыки понимания, осмысления и оценки воспринятой информации, понятийно-логическое мышление вытесняется «клиповым». Последнее характеризуется фрагментарностью, быстрым переключением с фрагмента на фрагмент, а так- же образностью и стереотипностью, позволяющими быстро схватывать суть дела. В стереотипном мышлении снижен рациональный, когнитивный компонент, вследствие чего утрачивается критичность и полнота восприятия, а также целостность понимания окружающей реальности. «Клиповое» мышление оперирует вырванными из контекста образами, словами, картинками, ему чужды сомнение и рефлексия, что порождает управляемое восприятие.

Причину появления клипового мышления видят в увеличивающемся потоке информации. На ее обработку и осмысление полученных знаний уже не остается времени: чтобы идти в ногу со временем, требуется постоянное информационное обновление. СМИ, телевидение, Интернет, радио заменяют смысл магией звучащего слова.

Современное постиндустриальное общество складывается, согласно американскому социологу Д. Беллу, в конце XX века в США, Японии, странах Западной Европы. Фундаментом системы общественного производства здесь становится труд, который направлен на получение, обработку и хранение информации [Белл 2004]. Для постиндустриального общества характерно целенаправленное усовершенствование техники и технологий на основе широкого применения научных разработок. В результате внедрения автоматизированных информационных систем в сферу материального производства в последней оказывается занятой значительно меньшая (по сравнению с индустриальной эпохой) доля работоспособного населения; доля занятых в сфере услуг и досуга, напротив, неуклонно растет. 
Существенное изменение соотношения времени работы и времени досуга произошло в конце XIX века в связи с созданием конвейера. Благодаря этому изобретению, идея которого была вызвана к жизни требованиями роста эффективности производства в условиях создания продуктов массового потребления, мускульная и интеллектуальная активность человека стали заменяться технологиями. Однако помимо позитивных изменений, которые произвело это изобретение (избавление от тяжелой работы и увеличение свободного времени), можно указать и на отрицательные последствия его влияния: место человека заняла машина, и человек оказался «свободен» от труда. В этой связи Э. Фромм отмечал, что каждодневный труд в современном мире потерял актуальность. Отдав свою жизнь в подчинение технике, человек утратил творческую составляющую, стал подобен роботу, который способен работать, но не творить. Трудовая деятельность больше не приносит человеку радости, потому что он лишен свободы, закабален техникой. Интересно, что разрешение этого противоречия Э. Фромм видит в любви. Он вспоминает притчу, в которой Бог объясняет Ионе, что «сущность любви - трудиться ради чего-нибудь и взрастить что-нибудь, что любовь и труд - нераздельны. Человек любит то, ради чего он трудится, и человек трудится ради того, что он любит» [Фромм 2006, 276].

Похожие изменения имели место в Древней Греции в $\mathrm{V}$ веке до н. э., в эпоху становления рабовладельческой демократии, когда появились новые формы общественного разделения труда: свободные греки получили досуг, а рабы выполняли физическую работу. Результатом стал расцвет архитектуры, скульптуры, прикладного творчества, литературы, театра, философии.

$\mathrm{XX}$ век также стал переходным этапом в процессе эволюции труда, что выразилось в смене ценностного отношения к нему. В эпоху индустриализации труд мыслился как то, что придает смысл существованию человека благодарю своей специфике, заключавшейся в том, что труд - это «а) деятельность, б) он имеет цель, в) направлен на создание материальных и духовных ценностей, г) ценности служат для удовлетворения потребностей, д) предполагает результат, е) требует усилия» [Хорошкевич web]. Напротив, в информационном обществе труд может выступать в качестве второстепенной деятельности, совместимой с другими ее видами. Многие люди, не выходя из дома, могут работать и при этом заниматься какими-то другими делами - например, смотреть любимые телепередачи, слушать музыку или общаться с друзьями. Также труд перестает быть альтернативой досугу. Показательно, что современные исследователи характеризуют общество цифровой эпохи как «когнитивный капитализм» и отмечают такие характерные для него тенденции, как «колонизация» нерабочего времени; сознательное включение в производство элементов игры, досуга и культурного потребления; изменение соотношения профессии и хобби (см.: [Маяцкий 2014 web]).

В современном обществе традиционные профессии, связанные с промышленным производством, становятся все менее популярными у молодежи. Среди вузовских специальностей на протяжении последних десятилетий наиболее востребованными остаются экономика, менеджмент, медицина, юриспруденция и IT-направления. Большую популярность в последнее время приобрели специальности, позволяющие занимать должности служащих государственных и муниципальных органов, правоохранительных, кредитно-финансовых и других учреждений, военнослужащих, работать в сферах торговли, транспорта, связи, а также политической сфере [Волков 2009, 29]. Как никогда высоко ценится труд, связанный с получением информации, ее обработкой и составлением аналитических отчетов. Копирайтеры, программисты, аналитики, работая с готовыми знаниями, создают новую информацию на основе полученной.

В современном обществе наблюдается формирование новых тенденций в отношении к труду. С одной стороны, часть населения (небольшая численно) может себе позволить не трудиться и жить за счет получения наследства, накопленных ранее средств и т. п. С другой стороны, жизнь большинства становится все более напряженной и трудоцентричной (несмотря на законодательное регулирование норм труда и занятости). Смысл существования для большинства людей по-прежне- 
му сводится к трудовой деятельности по созданию необходимых для жизни вещей. Выполняя большую по объему работу, часто работая сверхурочно в выходные и праздничные дни, кто-то стремится сделать карьеру, ктото выполняет свои семейные обязательства, кто-то пытается реализовать свою мечту и т. п. Такая ситуация может привести к распространению патологической зависимости от труда, трудоголизму, а использование робототехники и компьютерных технологий не сокращают трудозатраты, как полагали авторы социальных утопий.

Среди новых трудовых практик наиболее распространенной становится фрилансерство. Приверженцы такого вида труда в качестве положительных характеристик своей деятельности отмечают независимость, свободный график работы, возможность работы на дому, они могут самостоятельно выбирать заказы и партнеров и т. п. В век Интернета и высоких технологий нет необходимости быть привязанным к жесткому графику работы и конкретному рабочему месту. Рост числа фрилансеров привел к обсуждению на государственном уровне вопроса налогообложения таких работников, тем более что с каждым годом их становится все больше.

Другой новой формой трудовой деятельности является дауншифтинг. В последнее время в нашем обществе настойчиво пытаются навязать в качестве ценности все, что связано с понятием «успешность». Такая точка зрения разделяется далеко не всеми. Есть значительное число людей, для которых на первое место выходит душевный покой, возможность никому ничего не доказывать, жить, а не выживать. Они не гонятся за достатком, за успехом, для них ценность жизни заключается в занятии любимым делом, интересах семьи. Дауншифтинг представляет собой отказ от общепринятых, социально желательных целей, снижение темпа жизни, работу в собственное удовольствие, уменьшение личных потребностей.

Представителей дауншифтинга не пугает профессия дворника, скорее наоборот, привлекает работа на свежем воздухе, а не в душном офисе престижной фирмы. Они часто уезжают в глушь, живут в деревне, занимаются сельским хозяйством. Учитывая аграрные традиции, которые исторически и потенциально широко представлены в нашей стране, за счет дауншифтеров возможно было бы повысить привлекательность занятия сельским хозяйством, возделать заброшенные земли. При этом можно использовать положительный опыт Израиля, где хорошо себя зарекомендовали кибуцы.

Однако одной из главных проблем современного общества, на наш взгляд, является культивирование успеха без рассмотрения путей его достижения. Доминирующими поведенческими стандартами человека стали слоганы: «Бери от жизни все!» или «Добивайся личного успеха, достигай богатства, живи в достатке». Среди рекламных блоков часто присутствуют выражения: «Ты должен это попробовать!», «Ты этого достоин!» и т. п. В перечне ценностей прочные позиции получают такие, как «успех», «удовольствие», «могущество». Современное общество формирует у своих членов устойчивые потребительские установки. Г. Маркузе, описывая ситуацию с потребностями, разделяет их на ложные и истинные. «Большинство преобладающих потребностей (расслабляться, развлекаться, потреблять и вести себя в соответствии с рекламными образцами, любить и ненавидеть то, что любят и ненавидят другие) принадлежат к категории ложных потребностей» [Маркузе 1994, 154]. Новые общественные приоритеты, акцентированные на разумном эгоизме и пропагандирующие прагматические ценности, являются, на наш взгляд, причиной морально-психологического упадка нашего общества. На этот факт обращают внимание представители различных социальных групп. Так, например, на открытии IX Рождественских чтений в Государственном Кремлевском дворце игумен Иоанн (Экономцев) сказал: «...идеалы общества потребления, человеческий эгоцентризм, стремление к комфорту и наслаждениям, безудержная погоня за прибылью и вещами завели человечество в тупик» [Александров и др. web].

Человек, который не трудится, не только утрачивает свои профессиональные навыки. Отсутствие постоянной работы может привести к деградации личности, утрате смысложизненных ориентиров и росту нигилистичес- 
ких настроений. Трудоспособная молодежь, не имеющая стабильной работы, испытывающая неуверенность в завтрашнем дне, пересматривает свою систему ценностных предпочтений: происходит отказ от коллективизма в пользу индивидуализма, менее значимой становится ценность семьи, которая воспринимается как бремя. Поменялось и отношение к труду. Так, согласно социологическим опросам, которые были проанализированы и обобщены сотрудниками Центра Сулакшина в 20102014 гг., «более $10 \%$ опрошенных считают, что если человек имеет возможность присвоить себе результаты чужого труда, то он может это сделать. Более $30 \%$ опрошенных полагают, что человек не обязан зарабатывать себе на жизнь трудом, а может жить за счет сдачи в наем недвижимости, или иметь процент с капитала. Менее 10 \% высказались за то, что каждый человек должен зарабатывать себе на жизнь только собственным трудом» [Сулакшин, Сазонова, Хвыля-Олинтер 2014, 109-110]. В опросе учитывались данные ценностных предпочтений молодежи и общества в целом. Результаты исследования указывают на трансформацию ценностных установок: по мере возрастания досуга «человек работающий» превращается в «человека играющего» [Маклюэн 2007].

Современное российское общество нуждается в актуализации и популяризации фундаментальных, базовых ценностей: труда, образования, семьи, защиты Родины и др. Такие ценности, как «успех», «удовольствие», «могущество», сами по себе не несут отрицательной нагрузки, но проблема заключается в том, каким образом они достигаются. Нравственное воспитание молодежи должно быть направлено на утверждение в сознании идеи о том, что только через созидательный труд, через усилия по овладению профессией и т. п. возможно достижение успеха. Ценностное отношение к труду должно стать основанием, формирующим мотивацию к созидательной деятельности как главной возможности достижения личного успеха и процветания общества в целом.

\section{СПИСОК ЛИТЕРАТУРЫ}

Белл 2004 - Белл Д. Грядущее постиндустриальное общество. М.: Academia, 2004.
Волков 2009 - Волков Ю.Е. К выработке современного представления о сущности труда // Социологические исследования. 2009. № 3. С. 27-35.

Маклюэн 2007 - Маклюэн М. Понимание Медиа: внешние расширения человека. М.: Гиперборея: Кучково поле, 2007.

Маркузе 1994 - Маркузе Г. Одномерный человек. M.: Refl-book, 1994.

Маяцкий 2014 - Маяцฺкий М.A. Труд, знание и досуг в постиндустриальном обществе [Экономическая социология. 2014. T. 15, № 1] // https:// cyberleninka.ru/article/n/trud-znanie-i-dosug-vpostindustrialnom-obschestve.

Моль 2008 - Моль A. Социодинамика культуры. М.: Издательство ЛКИ, 2008.

Александров и др. web - Александров Ю.И. и др. Нравственность современного российского общества: психологический анализ. М.: Институт психологии РАН, 2012 // http:// www.iprbookshop.ru/47531.html.

Сулакшин, Сазонова, Хвыля-Олинтер 2014 - Сулакшин С.С., Сазонова Е.С., Хвыля-Олинтер А.И. Государственная политика защиты нравственности и СМИ: Рабочая книга для законодателя. М.: Наука и политика, 2014.

Тоффлер 2004 - Тоффлер Э. Третья волна. М.: АСТ, 2004.

Фромм 2006 - Фромм Э. Здоровое общество. М.: АСТ: Хранитель, 2006.

Хорошкевич web - Хорошкевич Н.Г. К вопросу изучения понятия «труд» [Психология, социология и педагогика. 2014. № 10] // http:// psychology.snauka.ru/2014/10/3734.

\section{REFERENCES}

Bell D., 2004. The coming post-industrial society. Moscow, Academia Publ.

Volkov Yu.E., 2009. To the development of a modern understanding of the essence of labor. Sociologicheskie issledovaniya, no. 3, pp. 27-35.

Maklyuehn M., 2007. Understanding Media: external expansion person. Moscow, Giperboreya Publ., Kuchkovo pole Publ.

Markuze G., 1994. One-dimensional man. Moscow, Refl-book Publ.

Maiatsky M.A., 2014. Labor, Knowledge and Leisure in Postindustrial Society. Ekonomicheskaja sociologija, Vol. 15, no. 1. URL: https:// cyberleninka.ru/article/n/trud-znanie-i-dosug-vpostindustrialnom-obschestve.

Mol' A., 2008. Socio-dynamics of culture. Moscow, Izd-vo LKI.

Aleksandrov Yu.I. et al. Morality of modern Russian society: psychological analysis. Moscow, 


\section{ФИЛ ОСОФИЯ}

Institut psihologii RAN, 2012. URL: http:// www.iprbookshop.ru/47531.html (accessed 21 October 2018).

Sulakshin S.S., Sazonova E.S., Hvylya-Olinter A.I., 2014. State policy for the protection of morality and the media. Working book for legislator. Moscow, Nauka i politika Publ.
Toffler E., 2004. Third wave. Moscow, AST Publ. Fromm E., 2006. Healthy society. Moscow, AST Publ. Horoshkevich N.G. To the question of studying the concept of "work". Psihologiya, sociologiya $i$ pedagogika, 2014, no. 10. URL: http:// psychology.snauka.ru/2014/10/3734 (accessed 1 October 2018).

\section{Information about the Author}

Roman A. Kobylkin, Candidate of Sciences (Philosophy), Associate Professor, Department of Philosophy, Volgograd Academy of the Ministry of Internal Affairs of Russia, Istoricheskaya St., 130, 400089 Volgograd, Russian Federation, roman.kobylkin@mail.ru, https://orcid.org/0000-0002-6463-004X

\section{Информация об авторе}

Роман Александрович Кобылкин, кандидат философских наук, доцент кафедры философии, Волгоградская академия МВД России, ул. Историческая, 130, 400089 г. Волгоград, Российская Федерация, roman.kobylkin@mail.ru, https://orcid.org/0000-0002-6463-004X 